\title{
Differentiating occipital neuralgia from migraine and tension-type headache
}

\author{
Diferenciando a neuralgia occipital da enxaqueca sem aura e da cefaleia do tipo tensional
}

\author{
Omar Franklin Molina ${ }^{1}$, Zeila Coelho Santos', Laura Martins', Bruno Ricardo \\ Simiāo ${ }^{4}$, Douglas Oliveira Andrade ${ }^{5}$ Sérgio Elias Cury ${ }^{6}$, Marcos Rank $^{7}$
}

\section{RESUMO}

Objetivo. Estabelecer diagnóstico diferencial nos indivíduos com distúrbios craniomandibulares e bruxismo apresentando sintomas e sinais de neuralgia occipital, cefaléia do tipo tensional e enxaqueca sem aura. Método. Analisamos 32 pacientes com neuralgia occipital (idade média $38 ; 75 \%$ feminino), 102 com cefaleia tensional (idade média 33; 92,2\% feminino) e 16 com enxaqueca sem aura (idade média $37 ; 56,3 \%$ feminino). Os sintomas específicos de dor de cabeça foram utilizados de acordo com a Classificação Internacional das Dores de Cabeça em pacientes com distúrbios craniomandibulares e bruxismo. Resultados. O grupo com occipital neuralgia apresentou mais náusea $(78,1 \%)$, vômito $(62,5 \%)$, fotofobia $(71,8 \%)$, pontada latejante $(53,1 \%)$, pontada $(78,1 \%)$, dor intensa $(93,7 \%)$, queimação $(68,8 \%)$ e sensibilidade do nervo occipital $(100 \%)$ do que o grupo com cefaleia tensional $(\mathrm{p}=0,0001)$. $\mathrm{O}$ grupo com occipital neuralgia apresentou mais pontada $(78,1 \%)$, queimaçáo $(68,8 \%)$ e sensibilidade do nervo occipital (100\%) do que o grupo com enxaqueca sem aura $(\mathrm{p}<0,05)$. O grupo com enxaqueca sem aura apresentou mais vômito $(94 \% ; p=0,03)$ e fotofobia $(100 \% ; p=0,02)$ do que o grupo com neuralgia occipital. Conclusáo. Náusea, vômito, fotofobia, dor latejante, em pontada, dor mais intensa, em queimação e sensibilidade sobre o nervo occipital, diferenciam a neuralgia occipital, enquanto que pontada, queimação e sensibilidade sobre o nervo occipital, diferenciam a neuralgia occipital da enxaqueca sem aura.

Unitermos. Occipital, Cefaleia do Tipo Tensional, Enxaqueca sem Aura, Autonômicos, Dor

Citaçáo. Molina OF, Santos ZC, Martins L, Simião BR, Andrade DO, Cury SE, Rank M. Diferenciando a neuralgia occipital da enxaqueca sem aura e da cefaleia do tipo tensional.

This study was carried out at UNIRG Division of Occlusion and Orofacial Pain Gurupi-TO.

1.DDS, MDS, Post Doct in Orofacial Pain, Professor and Researcher, UNIRG, Dental School, Gurupi-TO, Brazil.

2.DDS, MDS, Professor and Researcher in Orthodontics and Orofacial Pain, UNIRG, Dental School, Gurupi-TO, Brazil.

3.DDS, MDs, Ph.D, Director: CEPRENO, Ribeirão Preto-SP, Brazil

4.DDS, MDS, Professor and Researcher, UNIRG, Dental School, Gurupi-TO, Brazil

5.DDS, Graduate Student, Professor of Oral Surgery, UNIRG, Dental School, Gurupi-TO, Brazil.

6.DDS,MDS, Ph.D, Professor/Researcher UNIFOA, Dental School, Volta Redonda-RJ, Brazil.

7.DDS, Graduate MSD Student (SLM University), Professor/Researcher

UNIRG, Dental School, Gurupi-TO, Brazil.

\section{ABSTRACT}

Objective. To establish differential diagnosis in patients presenting occipital neuralgia, tension-type headache, and migraine with aura. Method. We analyzed 32 patients with Occipital neuralgia (mean age $=38.0$; females $=75 \%$ ), 102 with tension-type headache (mean age $=33.0$; females $=92.2 \%$ ), and 16 with migraine without aura (mean age $=37.0$; females $=56.3 \%$ ). The specific symptoms of headaches were used in according to International Classification of Headache Disorders (ICHD) in patients with for craniomandibular disorders and bruxing behavior. Results. Occipital neuralgia group presented more nausea $(78.1 \% ; \mathrm{p}=0.0001)$, vomiting $(62.5 \% ; \mathrm{p}=0.0001)$, photophobia $(71.8 \%$; $\mathrm{p}=0.0001)$, throbbing $(53.1 \%$; $\mathrm{p}=0.0001)$, stabbing pain (78.1\%; $\mathrm{p}=0.0001)$, severe pain $(93.7 \% ; \mathrm{p}=0.0001)$, burning $(68.8 \%$; $\mathrm{p}=0.0001)$, and occipital nerve tenderness $(100 \% ; \mathrm{p}=0.0001)$ than tension-type headache group. Occipital neuralgia group showed more stabbing $(78.1 \%$; $=0.0001)$, burning $(68.8 \% ; \mathrm{p}=0.0005)$, and occipital nerve tenderness $(100 \% ; \mathrm{p}=0.0001)$ than migraine without aura group. Migraine without aura group showed more vomiting $(94 \% ; \mathrm{p}=0.03)$ and photophobia $(100 \% ; \mathrm{p}=0.02)$ than occipital neuralgia group. Conclusions. Nausea, vomiting, photophobia, throbbing, stabbing, severer pain, a burning description and occipital nerve tenderness, better differentiated occipital neuralgia from tension-type headache. Stabbing pain, burning and occipital nerve tenderness, better differentiated occipital neuralgia from migraine without aura.

Keywords. Occipital, Tension-Type headache, Migraine without Aura, Autonomic, Pain

Citation. Molina OF, Santos ZC, Martins L, Simião BR, Andrade DO, Cury SE, Rank M. Differentiating occipital neuralgia from migraine and tension-type headache. 


\section{INTRODUCTION}

Chronic pain conditions in the head, face or neck, have been considered a confusing area with a paucity of progress in the understanding of the pathophysiology of craniofacial pain. Clearly, there is increasing need to develop a widely accepted classification system in order to better understand chronic pains in the face, head, and neck $^{1}$. Headache is one of the most common complaints brought to doctors in most countries ${ }^{2}$ and researchers now consider occipital neuralgia $(\mathrm{ON})$ as a subset of cervicogenic headache disorders involving structures innervated by $\mathrm{C} 1, \mathrm{C} 2, \mathrm{C} 3$, and the trigeminal nerve $(\mathrm{TN})$, including the posterior scalp, periorbital, temporal, lower jaw, external ear, mastoid, neck and shoulder regions ${ }^{3}$. The greater occipital nerve (GON) arises from the dorsal ramus of $\mathrm{C} 2$, provides cutaneous innervations to the major portion of the posterior scalp and originates in the posterior neck lateral to the atlanto-axial joint and deep to the oblique inferior muscle where a communicating branch from the third cervical nerve may join the GON ${ }^{4}$. Anatomically, there are complex connections between C1, C2, and C3 sensory pathways and the TN sub-nucleus caudalis 5 .

The etiology of $\mathrm{ON}$ is related with a multiplicity of factors including whiplash injury, compression of the GON between the atlas, axis and upper cervical roots by arthritic changes in the spine ${ }^{6}$, severe trauma to the greater or lesser occipital nerves, degenerative spinal changes, cervical disc disease and tumor affecting C2/C3 nerve roots ${ }^{2}$. Clinically, $\mathrm{ON}$ is described as unilateral or bilateral paroxysmal, lancinating, stabbing or shooting, throbbing, burning, intermittent, electric-shock like, continuous and/or intermittent pain of moderate to severe intensity, usually short lasting, with diminished sensation in the distribution of the GON and/or lesser occipital nerves, presenting with a pain generator area in the occipital/sub-occipital region associated with a tender local area, pain reproduced with pressure over the pain generator area, and usually radiating to the vertex, frontal, orbital, and peri-orbital regions ${ }^{2,4,6}$. In many cases, pain in $\mathrm{ON}$ is so intense that radiation to the neck and face is reported frequently and may be disabling and refractory to conventional treatment ${ }^{7}$. Signs and symptoms of $\mathrm{ON}$ may mimic those occurring in the anatomic area innervated by the $\mathrm{TN}^{8}$. Some patients report pain behind the eye, in the middle facial third and in the frontal and temporal regions; a territory of the fifth cranial nerve ${ }^{2}$.

The ganglia of C2 and C3 interconnect with TN ganglion in the brainstem, thus, ON may refer pain to any TN branch, especially to the retro-orbital area' ${ }^{9}$ TN main sensory nucleus interconnects with the substantia gelatinosa of the upper cervical spinal cord via the nucleus of the spinal tract of the fifth cranial nerve ${ }^{10}$.

Migraine without aura (MWA) is a high prevalent recurring neurologic disorder characterized by headache, autonomic, somatosensory symptoms ${ }^{11}$, typically described as unilateral pulsating headache of moderate to severe intensity, steady, throbbing, aggravated by physical activity, with nausea, vomiting, sensitivity to light and sounds as concomitant symptoms ${ }^{12,13}$. Tension type-headache (TTH), is mild to moderate headache bilateral, dull, constant pain lasting 30 minutes to seven days, usually reported as pressure, constricting or a tight sensation, reported typically on both sides of the head or around the head in a "band-like distribution" and sometimes associated with nausea ${ }^{12,13}$.

Because ON may occur frequently in orofacial pain patients, there is an overlap of signs and symptoms in different types of headache, the differential diagnosis is a challenge even to the experienced practitioners. As there are few studies to differentiate such headaches, the aim of this study is to assess the frequency of specific symptoms in ON, TTH and MWA in patients with craniomandibular disorders (CMDs) and bruxing behavior (BB).

\section{METHOD}

\section{Sample}

From a large group of individuals presenting with CMDs and BB referred consecutively over a period of 10 years to UNIRG, University Center, Division of Orofacial Pain and Occlusion, for diagnosis and treatment, the charts of all those presenting ON ( $\mathrm{n}=32)$, MWA, $(\mathrm{n}=16)$ and TTH $(\mathrm{n}=102)$ were reviewed retrospectively so as to gather information about the presence or absence of those disorders by an expert in the field (Omar Franklin Molina). The investigation was approved by the Ethical Committee of the Dental School (001-2013). 


\section{Procedure}

Patients were classified as presenting CMDs if they demonstrated at least three of the following signs, symptoms or behaviors ${ }^{14}$ : a complaint of pain in the masticatory muscles and/or temporomandibular joints $(\mathrm{TMJ} s)$, difficulties to perform normal jaw movements, tenderness to palpation of joint and muscles, joint noises, seeking active treatment for their complaint and headaches usually of $\mathrm{CMD}$ origin. $\mathrm{BB}$ signs and symptoms are very different from those present in CMDs and include but are not restricted to the following: patient's report of catching herself/himself clenching the teeth during the day, a report of masseter muscle fatigue during the day, patient's report of masseter muscle fatigue on awakening in the morning, masseter muscle tension during the day, masseter muscle tension on awakening in the morning, patient's report of catching herself/himself grinding or clenching at night, a feeling of jaw locking on awakening at night or in the morning, and tooth wear, specifically on the anterior lower teeth on visual inspection. It has been demonstrated that higher scores in $\mathrm{BB}$ correspond to more severe CMDs including TMJs internal derangements (TMJs-ID) ${ }^{15}$. Additionally, the comprehensive protocol used in the current study contains a number of descriptors to describe different pain types including those evaluated in the current study. Criteria to consider the presence of "multiple painful sites" in ON, TTH and MWA were: patient's report of four or more head painful sites.

Criteria to exclude CMDs and BB patients presenting with the three headache types from participating in this study were the presence of severe psychiatric disorders and/or neurologic disease (for instance, epilepsy, Parkinson's disease), and intellectual difficulties to respond properly to questionnaires. Because this was a comparison study assessing clinical diagnostic differences between those $\mathrm{CMDs}$ and $\mathrm{BB}$ patients presenting with $\mathrm{ON}, \mathrm{TTH}$ ) and MWA, a control group without pain was not used in the current investigation.

\section{Statistical Analysis}

Statistical methods deemed to be appropriate for this investigation were Kruskal-Wallis non parametric ANOVA to evaluate age differences in headache groups and Fisher' s exact test to assess frequency of symptoms in three different pain groups.

\section{RESULTS}

Demographic data in 150 CMDs patients show that females predominated in the groups presenting the three types of headaches and CMDs. Mean ages in such groups were about $38.0(\mathrm{ON}), 33.0(\mathrm{TTH})$, and 37.0 (MWA). Age was not different in the three experimental groups ( $\mathrm{p}=0.17$, Table 1 ).

When comparing some specific symptoms in $\mathrm{ON}$ and TTH we found that more patients in $\mathrm{ON}$ group presented $78.1 \%$ nausea $(\mathrm{p}<0.0001)$; 62.5 vomiting $(\mathrm{p}<0.0001) ; 71.8 \%$ with photophobia $(\mathrm{p}<0.0001)$; $53.1 \%$ "pulsating/throbbing” pain $(\mathrm{p}<0.0001) ; 78.1 \%$ stabbing/shooting/jabbing pain $(\mathrm{p}<0.0001) ; 21.8 \%$ electric shock-like pain $(\mathrm{p}<0.0001) ; 34.4 \%$ numbness $(\mathrm{p}<0.0001) ; 93.7 \%$ severe pain $(\mathrm{p}<0.0001) ; 46.9 \%$ multiple painful areas $(\mathrm{p}<0.0001) ; 68.8 \%$ burning pain $(\mathrm{p}<0.0001) ; 40.6 \%$ dizziness $(\mathrm{p}<0.0001) ; 31.2 \%$ blurred vision $(\mathrm{p}<0.0001) ; 100 \%$ localized pain in the pain generator area $(\mathrm{p}<0.0001) ; 40.6 \%$ nasal congestion $(\mathrm{p}<0.0001)$, and $34.4 \%$ nasal occlusion $(\mathrm{p}<0.0001$; Table 2).

When comparing the same symptoms in $\mathrm{ON}$ and MWA, patients in MWA group presented 100\% nausea ( $\mathrm{p}<0.07)$, 94\% vomiting $(\mathrm{p}<0.03)$, and $100 \%$ photophobia $(\mathrm{p}<0.02)$. ON patients presented $78.1 \%$ stabbing/ shooting pain $(\mathrm{p}<0.0001), 34.4 \%$ numbness $(\mathrm{p}<0.008)$, $46.9 \%$ pain in multiple areas $(\mathrm{p}<0.05), 68.6 \%$ burning pain $(\mathrm{p}<0.0005), 40.6 \%$ dizziness $(\mathrm{p}<0.002), 31.2 \%$ blurred vision $(\mathrm{p}<0.01)$, and $100 \%$ localized tenderness in the pain generating area $(\mathrm{p}<0.0001$; Table 3$)$.

\begin{tabular}{lccc}
\hline & $\begin{array}{c}\text { ON } \\
\mathbf{n}=\mathbf{3 2}\end{array}$ & $\begin{array}{c}\text { TTH } \\
\mathbf{n = 1 0 2}\end{array}$ & $\begin{array}{c}\text { MWA } \\
\mathbf{n = 1 6}\end{array}$ \\
\cline { 2 - 4 } & $\mathbf{N ~ ( \% )}$ & $\mathbf{N ~ ( \% )}$ & $\mathbf{N}(\mathbf{\%})$ \\
\hline Females & $28(87.5)$ & $94(92.2)$ & $9(56.3)$ \\
Males & $4(12.5)$ & $8(7.8)$ & $7(43.7)$ \\
\hline Mean Age & 38.0 & 33.0 & 37.0 \\
Standard & 11.5 & 11.9 & 11.9 \\
Deviation & & & \\
Range & $18-75$ & $14-61$ & $18-61$ \\
\hline
\end{tabular}

Table 1. Socio-demographic data in those individuals presenting with occipital neuralgia $(O N)$, tension type-headache (TTH), and migraine without aura (MWA). 
Table 2. Frequency of specific clinical signs or symptoms in occipital neuralgia (ON) and tension type-headache (TTH).

\begin{tabular}{cccc}
\hline \multirow{2}{*}{ Signs/Symptoms } & $\mathbf{O N}$ & $\mathbf{T T H}$ & \\
\cline { 2 - 4 } Nausea & $25(78.1)$ & $39(38.2)$ & 0.0001 \\
Vomiting & $20(62.5)$ & $7(6.8)$ & 0.0001 \\
Photophobia & $23(71.8)$ & $29(28.4)$ & 0.0001 \\
Throbbing & $17(53.1)$ & $4(3.9)$ & 0.0001 \\
Stabbing/Shooting/Jabbing & $25(78.1)$ & $0(0.0)$ & 0.0001 \\
Electric-Shock & $7(21.8)$ & $0(0.0)$ & 0.0001 \\
Numbness & $11(34.4)$ & $0(0.0)$ & 0.0001 \\
Severe pain & $30(93.7)$ & $0(0.0)$ & 0.0001 \\
Multiple painful areas & $15(46.9)$ & $13(12.7)$ & 0.0001 \\
Burning & $22(68.8)$ & $0(0.0)$ & 0.0001 \\
Dizziness & $13(40.6)$ & $0(0.0)$ & 0.0001 \\
Blurred vision & $10(31.2)$ & $0(0.0)$ & 0.0001 \\
Occipital nerve Tenderness & $32(100.0)$ & $0(0.0)$ & 0.0001 \\
Nasal congestion & $13(40.6)$ & $0(0.0)$ & 0.0001 \\
Nasal Occlusion & $11(34.4)$ & $0(0.0)$ & 0.0001 \\
\hline
\end{tabular}

\section{DISCUSSION}

\section{Frequency of specific signs and symptoms in $\mathrm{ON}$ as compared to TTH}

In the current investigation, we found that nausea, vomiting, photophobia, a pulsating pain, a jabbing/ shooting description, electric shock-like pain, numbness, more severe pain in multiple areas, a burning description, dizziness, blurred vision, tenderness, allodynia in a pain generator area, and nasal congestion/occlusion occurred much more frequently in $\mathrm{ON}$ patients as compared to TTH ones. Data in the current study also indicate that both neuropathic and autonomic symptoms are more frequent and such characteristics better differentiate $\mathrm{ON}$ patients from those presenting TTH. The outcome in the current study concurs with those of previous investigations ${ }^{16,17}$ indicating that $\mathrm{ON}$ is a true neuralgic/neuropathic disorder with paroxysmal episodes of shooting electric-like symptoms occurring in the distribution of the GON and/or lesser occipital nerves and suggesting that differential diagnosis is not difficult. Because $\mathrm{ON}$ is a true neuropathic pain, pharmacologic treatment for cervicogenic headache and $\mathrm{ON}$ includes medications for the prevention of neuropathic pain ${ }^{18}$.
The outcome in the current study has additional support in another research ${ }^{2}$, indicating that burning, throbbing, shooting and the presence of a tender/painful area in the sub-occipital region, are more typical of $\mathrm{ON}$ patients. Extreme localized tenderness is often found upon palpation over the occipital notches with reproduction of focal and radiating pain ${ }^{17}$. Although trigger points associated tenderness in the neck also occurs frequently in TTH patients, the pain generating area, is not observed in such patients. Even though ON may be described bilaterally anterior and posterior in the head, such a disorder occurs more commonly in one side of the head as compared to TTH, which is usually described bilaterally. A pain generator allodynic sub-occipital area is the landmark of ON and is rarely observed in TTH patients. Pressure over the occipital nerves may amplify the pain in ON patients, but there is usually no clear trigger ${ }^{2}$. Descriptions such as burning, severe, shooting, and the presence of a pain generating area in the posterior scalp $p^{2,19}$, are frequently reported by $\mathrm{ON}$ patients and rarely by TTH cases. When patients use descriptors such as intermittent, jabbing or throbbing and the presence of a pain generating sub-occipital area is observed clinically, the presence of ON should be suspected6. All patients in the current study described $\mathrm{ON}$ as very intense, severe

Table 3. Frequency of specific clinical signs or symptoms in occipital neuralgia $(O N)$ and migraine without aura (MWA).

\begin{tabular}{cccc}
\hline \multirow{2}{*}{ Signs/Symptoms } & $\mathbf{O N}$ & $\mathbf{T T H}$ & \\
\cline { 2 - 4 } Nausea & $25(78.1)$ & $16(100.0)$ & 0.07 \\
Vomiting & $20(62.5)$ & $15(94.0)$ & 0.03 \\
Photophobia & $23(71.8)$ & $16(100.0)$ & 0.02 \\
Throbbing & $17(53.1)$ & $12(75.0)$ & 0.21 \\
Stabbing/Shooting/Jabbing & $25(78.1)$ & $2(12.0)$ & 0.0001 \\
Electric-Shock & $7(21.8)$ & $0(0.0)$ & 0.07 \\
Numbness & $11(34.4)$ & $0(0.0)$ & 0.008 \\
Severe pain & $30(93.7)$ & $14(87.5)$ & 0.59 \\
Multiple painful areas & $15(46.9)$ & $2(12.5)$ & 0.05 \\
Burning & $22(68.8)$ & $1(6.2)$ & 0.0005 \\
Dizziness & $13(40.6)$ & $0(0.0)$ & 0.002 \\
Blurred vision & $10(31.2)$ & $0(0.0)$ & 0.01 \\
Occipital nerve Tenderness & $32(100.0)$ & $0(0.0)$ & 0.0001 \\
Nasal congestion & $13(40.6)$ & $4(25.00$ & 0.35 \\
Nasal Occlusion & $11(34.4)$ & $4(25.0)$ & 0.74 \\
\hline
\end{tabular}


or unbearable and these descriptors were rarely used by TTH patients. ON pain is very severe ${ }^{2}$ and TTH pain is usually described as mild or moderate ${ }^{16,20}$.

\section{Frequency of symptoms in ON as compared to MWA}

In the current study, we found that the frequencies of nausea, a pulsating quality, electric shock-like, severe pain, nasal congestion and nasal occlusion were not different in $\mathrm{ON}$ and MWA patients. We found a frequency of $40.6 \%$ nasal congestion in occipital neuralgia (ON) patients and 25\% in MWA patients. Thus, the results of this study are supported by one investigation reporting that nasal congestion is present in less than $45 \%$ of MWA patients $^{21}$. Vomiting and photophobia were observed much more frequently in MWA patients as compared to $\mathrm{ON}$ ones. As a whole, it seems that there is no difference in autonomic symptoms when comparing both headache types. It may be that severe pain present in both disorders is associated with the predominance of autonomic symptoms and that severe pain stimulates certain subsets of neurons in the central nervous system which in turn enhances other anatomic areas responsible for the development of autonomic symptoms. The current data also indicate that jabbing pain, numbness, pain in multiple anatomic zones, burning, dizziness, blurred vision and the presence of a sub-occipital "pain generator area", are common characteristics in $\mathrm{ON}$.

The outcome in the current study is in accordance with previous investigations $s^{2,3,6,19}$ indicating that neuropathic features including a burning, throbbing and shooting quality, presence of a sub-occipital pain generator area, numbness, jabbing, dizziness and a positive response to local anesthetic blocks, are clinical characteristics of $\mathrm{ON}$. It is noteworthy to mention that even though $\mathrm{ON}$ is typically a neuropathic pain, only $21.8 \%$ of ON patients in the current study described their pain as electric-shock like. It may be that pain quality in patients with such a disorder, is duration and/or intensity dependent. 34.4\% of $\mathrm{ON}$ patients reported the presence of numbness and this outcome is in line with one case series study ${ }^{3}$, reporting that tingling/paresthesia is not found in all $\mathrm{ON}$ patients ${ }^{3}$.

\section{Symptoms that differentiate ON from MWA}

Based on the results of the current study, it is apparent that neuropathic rather than autonomic symptoms better differentiate ON from MWA. Descriptions of jabbing, electric-shock like, burning, dizziness and the presence of allodynia in the "pain generator area", were observed much more frequently in $\mathrm{ON}$. These symptoms could be used by the novice and experienced clinician to establish a diagnosis and differentiate ON from MWA. This assumption and observations are echoed by other investigations ${ }^{2,6,18,22}$ indicating that $\mathrm{ON}$ is a true neuropathic pain described in the sub-occipital, frontal, temporal, and orbital areas of the head.

MWA and $\mathrm{ON}$ are headache pains described as very intense, with the presence of many autonomic symptoms. However, pain in MWA is less severe, it occurs more frequently in the anterior/lateral region of the head, whereas pain in $\mathrm{ON}$ is always described as very intense occurring in both the anterior and posterior region of the head. Both ON and MWA present with many autonomic symptoms. However, there is a predominance of neuropathic symptoms in $\mathrm{ON}$ as compared to MWA. Thus, the presence of neuropathic symptoms should be used by the pain clinician to differentiate $\mathrm{ON}$ from $\mathrm{MWA}^{8}$. Even though throbbing and nausea are observed frequently in both ON and MWA, the presence of a burning, jabbing, intermittent, a shooting description and the "pain generator area" commonly observed in ON patients, should alert the astute clinician to differentiate one headache from the other ${ }^{2}$.

The clinical relevance of different clinical presentations and probably different etiological factors in $\mathrm{ON}$, MWA and TTH points to differential management strategies. $\mathrm{ON}$ is better treated with injections of bupivacaine $0.5 \%$ into the muscles of the occipital region along the nuchal line, thus blocking superficial occipital nerves which may bring immediate headache relief ${ }^{23}$. When anesthetic blockade and neurolytic procedures are used, a course of physical therapy and rehabilitation is recommended to enhance functional restoration and affect a longer lasting analgesic effect ${ }^{24}$. Other techniques including implantable electrodes for intractable $\mathrm{ON}^{25}$, and 
medication frequently used for neuropathic disorders may also be of great value in $\mathrm{ON}$ patients. As for migraine, its etiology is not clearly understood, however, there is evidence that psychological factors play a major role, thus, counseling, psychotherapy and medication for anxiety, stress and depression are highly indicated ${ }^{26}$. MWA may also be aggravated by muscle tension and cervicogenic disorders, thus, electrical stimulation in the cervical region may be very helpful ${ }^{11}$. Abortive migraine medication such as triptans, beta-blockers, calcium channel blockers, NSAIDS, ergot derivatives and antidepressants are also commonly used as preventive treatment for migraine $^{12}$.

TTH presents with significant neck pain and tension in the muscles of the neck, shoulders and upper back $^{21}$ and is usually viewed as a form of myofascial pain, thus, medication for neuromuscular and CMDs including muscle relaxants, antidepressants and anti-anxiety agents for anxiety and BB are strongly indicated. Stress, depression and even somatoform disorders are commonly observed in TTH patients ${ }^{27}$, thus, psychological treatment, local anesthesia for trigger points, massage and electrical stimulation are also indicated and may be also helpful in the treatment of $\mathrm{BB}$ and CMDs. Because the frequencies of ON, TTH and MWA are very high among $\mathrm{CMDs}$ and $\mathrm{BB}$ individuals, the astute clinician should refer such patients for neurological assessment.

\section{CONCLUSION}

Based on the results of the current study and the review of the literature, there are reasons to believe that intensity, laterality of pain and the presence of many autonomic symptoms in MWA, better differentiate such a headache from TTH. On the other hand, because autonomic symptoms are predominant in both $\mathrm{ON}$ and MWA, they are not useful to establish a differential diagnosis. It is apparent that neuropathic symptoms observed very frequently in $\mathrm{ON}$, better differentiate this headache from MWA. The presence of a "pain generator area" in the sub-occipital area is observed only in $\mathrm{ON}$ patients. Because MWA may also present trigger points in the sub-occipital area, and tenderness rather than a "pain generator area", is more frequently found, thus, the absence of a pain generator area in MWA may be used as a diagnostic tool to differentiate one headache from the other.

Limitations of this investigation: Because the strength of a statistical test depends on sample size, and we evaluated only 16 MWA individuals, this relatively small sample may to a certain extent influence the results of the statistical tests herein used, and thus, limit the generalization of the results. Consequently, the results of this investigation should be examined with caution. Studies using larger samples of MWA patients should be carried out in order to replicate the results reported in the current investigation.

\section{REFERÊNCIAS}

1.Ruiz-López R, Erdine S. Treatment of cranio-facial pain with radiofrequency procedures. Pain Pract 2002;2:206-13. http://dx.doi.org/10.1046/j.15332500.2002.02025.x

2.Barna S, Hashmi M. Occipital neuralgia. Pain Manage Rounds 2004;1(7):16.

3.Yi X, Cook AJ, Hamill-Ruth RJ, Rowlingson JC. Cervicogenic headache in patients with presumed migraine: missed diagnosis or misdiagnosis? Pain 2005;6:700-3. http://dx.doi.org/10.1016/j.jpain.2005.04.005

4.Ward JB. Greater occipital nerve block. Semin Neurol 2003;23:59-62. http://dx.doi.org/10.1055/s-2003-40752

5.Franzini A, Messina G, Leone M, Broggi G. Occipital nerve stimulation (ONS). Surgical technique and prevention of late electrode migration. Acta Neurochir 2009;151:861-5. http://dx.doi.org/10.1007/s00701-009-0372-8 6.Sahai-Srivastava S, Zheng L. Occipital neuralgia with and without migraine: Difference in pain characteristics and risk factors. Headache 2011;51:1248. http://dx.doi.org/10.1111/j.1526-4610.2010.01788.x

7.Ducic I, Hartman EC, Larson EE. Indications and outcomes for surgical treatment of patients with chronic migraine headaches caused by occipital neuralgia. Plast Reconst Surg 2009;123:1453-60. http://dx.doi.org/10.1097/ PRS.0b013e3181a0720e

8. Weiss C, Meza N, Rojo A, Hernández J. Neuralgia occipital (Arnold): Relato de dos casos y revisión de la literatura. Rev Memo Com 2009;3:8-16.

9.Evans RW. Diagnostic testing for headache. Med Clin North Am 2001;85:865-85.

10.Kapoor V, Rothfus WE, Grahovac SZ, Stephen Z, Kassam A. Horowitz MW. Refractory occipital neuralgia: Preoperative assessment with CT guided nerve block prior to dorsal cervical rhyzotomy. AJNR Amer J Neuroradiol 2003;24:2105-10.

11.Piovesan EJ, Di Stani F, Kowacs A, Mulinari RA, Radunz VH, Utiumi M, et al. Massaging over the greater occipital nerve reduces the intensity of migraine attacks. Arq Neuropsiquiatr 2007;65:599-604. http://dx.doi.org/10.1590/ $\underline{\text { S0004-282X2007000400010 }}$

12.Mehta SA, Epstein JB, Greene C. Recognition and management of headache. JCDA 2006;72:835-9.

13.The International Classification of headache disorders: 2nd edition. Headache Classification Subcommittee of the International Headache Society. Cephalalgia 2004;24(Suppl 1):9-160. http://dx.doi.org/10.1111/j.14682982.2003.00824.x

14.Molina OF, Peixoto MG, Eid NL, Aquilino RN, Rank RC. Headache and bruxing behavior types in craniomandibular disorders (CMDs) patients. 
Rev Neurocienc 2011;19: 449-57.

15.Molina OF, dos Santos J, Nelson SJ, Nowlin T. A clinical study of signs and symptoms of CMDs in bruxers classified by the degree of severity. J Craniomand Pract 1999; 17:268-79.

16.Skaribas I, Aló K. Ultrasound imaging and occipital nerve stimulation. Neuromodulation 2010;13:126-30. http://dx.doi.org/10.1111/j.15251403.2009.00254.x

17. Weiner RL, Reed KL. Peripheral stimulation for control of intractable occipital neuralgia. Neuromodulation 1999;2:217-21. http://dx.doi.org/10.1046/ j.1525-1403.1999.00217.x

18.Yadla S, Ratliff SJ., Harrop JS. Whiplash: Diagnosis, treatment and associated injuries. Curr Rev Musculoskelet Med 2008;1:65-8. http://dx.doi. org/10.1007/s12178-007-9008-x

19.Rampello L, Vecchio I, Migliore M, Malaguarnera M, Malaguarnera G. The most frequent and surgical neuralgias: physiopathology and clinical pictures. Acta Med Medit 2012;28:109-11.

20.Pielsticker A, Haag G, Zaudig M, Lautenbacher S. Impairment of pain inhibition in chronic tension-type headache. Pain 2005;118:215-23. http:// dx.doi.org/10.1016/j.pain.2005.08.019
21.Nadkar MY, Desai SD, Itolikar MW. Migraine: Pitfalls in the diagnosis. JAPI;2010;58:10-3.

22.Gabrhelik T, Michálek P, Adamus M. Pulsed radiofrequency therapy versus greater occipital nerve block in the management of refractory cervicogenic headache: a pilot study. Prague Med Rep 2011;112:279-87. http://dx.doi. org/10.1016/S1754-3207(11)70669-1

23.Bano I, Chaudhary WA, Ashfaq M. Interventional pain management techniques can be helpful in headache management. Anaesth Pain Intens Care 2011;15:60-4.

24.Biondi DA. Cervicogenic headache: Diagnostic evaluation and treatment strategies. Pain Manag Rounds 2004;1:1-6.

25.Magown P, Garcia R, Beauprie I, Méndez IM. Occipital nerve stimulation for intractable occipital neuralgia: An open surgical technique. Clin Neurosurg 2009;56:119-24.

26. Waldie KE, Poulton R. Physical and psychological correlates of primary headache in young adulthood: A 26 year longitudinal study. J Neurol Neurosurg Psychiatry 2002;72:86-92. http://dx.doi.org/10.1136/jnnp.72.1.86 27.Tsuboi K. Tension-type headache. JMAJ 2002;45:202-6. 